\title{
La activa participación de las Madres Mayores del Hospital del Santo Cristo de los Dolores (Pozo Santo) bajo la administración dela Hermandad de la Misericordia de Sevilla
}

\section{The active participation of the Greater Mothers of the Hospital of Santo Christ of the Pains (Pozo Santo) under the administracion dela Fraternity of the Mercy of Seville} A ativa participação das Mães Maiores do hospital do Santo Cristo das Dores (Poço Santo) baixo a administracion de la Hermandad da Misericordia de Sevilla

\author{
Paula Ermila Rivasplata Varillas \\ Doctora en Europa, mundo mediterráneo y su difusión Atlántica. Doctora en Historia de América. \\ Universidad Pablo Olavide de Sevilla.
}

Cómo citar este artículo en edición digital: Rivasplata Varillas, P.E. (2017). La activa participación de las Madres Mayores del Hospital del Santo Cristo de los Dolores (Pozo Santo) bajo la administración de la Hermandad de la Misericordia de Sevilla. Cultura de los Cuidados (Edición digital) 21,47. Recuperado de http://dx.doi.org/10.7184/cuid.2017.47.10

Correspondencia: Departamento de Historia de América. Facultad de Geografía e Historia. Universidad de Sevilla. C/Doña María de Padilla, s/n.

Correo electrónico: rivasplatavarillas@gmail.com.

Recibido: 09/05/2016; Aceptado: 12/10/2016

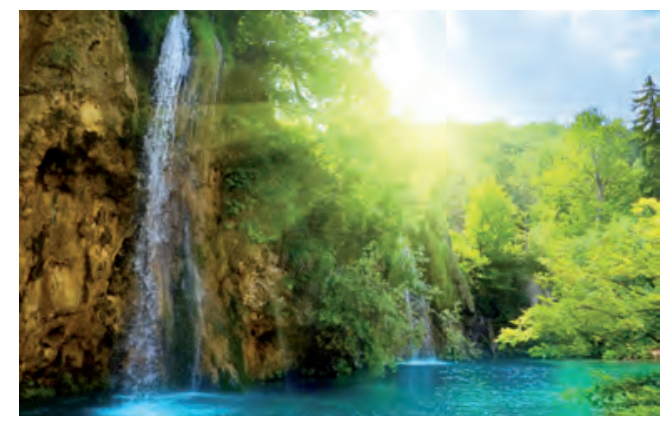

\section{ABSTRACT}

The major mother of the Holy Well hospital-sanctorum fulfilled a transcendental paper in the maintenance of that institution. Even exceeded its functions, proposing, suggesting and making proposals even without the permission of his patronage that was the Brotherhood of the Mercy that was directing the Pious House of analogous name. The free interference of the major mother in the management of Holly Well often allowed by the Mercy provoked for the bishopric the first problem of consideration as the dismissal of the major mother Feliciana of Holy Teresa and chaplain at the request of vicar the Brotherhood of Mercy obeyed in 1737. However, soon after the incident, the same major mother proposed by the vicar resumed her leadership role absolutely necessary to maintain the Pozo Santo and the brotherhood of Mercy understood and accepted.

Palabras claves: Major mother, sanctorum, hospital, Holy Well, Brotherhood of Mercy, Sevilla.

\section{RESUMO}

A mãe maior do hospital beaterio do Poço Santo cumpriu um papel trascendental na manutenção daquela instituição. Inclusive rebaso 
suas funções, propondo, sugerindo e realizando propostas inclusive sem a permissão de sua patronato, a Hermandad da Misericordia, que dirigia a Casa Pía de análogo nome. A livre intromisión da mãe maior na gestão do Poço Santo muitas vezes permitida pela Misericordia provocou pelo obispado o primeiro problema de consideração que género o despedimento da mãe maior Feliciana de Santa Teresa e do capellán do Poço Santo a pedido do provisor que acatou a fraternizem da Misericordia em 1737. No entanto, ao pouco tempo do incidente, a mesma mãe maior proposta pelo provisor voltou a assumir seu papel de liderança absolutamente necessária para a manutenção do beaterio e que a hermandad da Misericordia entendia e aceitava.

Palavras-chave: Mãe maior, beaterio, hospital, Poço Santo, Hermandad da Misericordia, Sevilla.

\section{RESUMEN}

La madre mayor del hospital beaterio del Pozo Santo cumplió un papel trascendental en el mantenimiento de aquella institución. Incluso rebaso sus funciones, planteando, sugiriendo y realizando propuestas incluso sin el permiso de su patronato, la Hermandad de la Misericordia, que dirigía la Casa Pía de análogo nombre. La libre intromisión de la madre mayor en la gestión del Pozo Santo muchas veces permitida por la Misericordia provocó por el obispado el primer problema de consideración que género el despido de la madre mayor Feliciana de Santa Teresa y del capellán del Pozo Santo a pedido del provisor que acató la hermanad de la Misericordia en 1737. Sin embargo, al poco tiempo del incidente, la misma madre mayor propuesta por el provisor volvió a asumir su papel de liderazgo absolutamente necesario para el mantenimiento del beaterio y que la hermandad de la Misericordia entendía y aceptaba.

Palabras claves: Madre mayor, beaterio, hospital, Pozo Santo, Hermandad de la Misericordia, Sevilla.

\section{INTRODUCCIÓN}

El hospital del Cristo de los Dolores, conocido como del Pozo Santo, está ubicado en una plazuela del mismo nombre y había sido fundado en 1666 por las beatas terciarias franciscanas María de Jesús y Beatriz de la Concepción (Ortiz de Zúñiga, 1796, pp. 72-73 y 370-372) (Collantes, 1884: 207-230) (Gonzales, 2003) (Gonzales, 1967) (Roda, 2005: 321). La hermandad de la Misericordia tuvo a su cargo el patronato y administración del beaterio, destinado a mujeres impedidas e incurables desde la segunda mitad del siglo XVII (Carmona García, 1989: 69). El Pozo Santo debía ser mantenido, cuidado, asistido y administrado con la economía y buen gobierno necesario para lo cual dos miembros de la hermandad de la Misericordia eran elegidos anualmente para ejercer de diputados y tener al tanto a su cabildo sobre los asuntos del beaterio.

La madre mayor, el capellán, las beatas y las enfermas vivían en el beaterio hospital del Pozo Santo y estaba especializada en incurables, impedidas y desamparadas que esperaban un buen morir cristiano. En este caso, el capellán y las beatas, como sus ayudantes, estaban entrenados en aliviar y reconfortar espiritualmente a las enfermas como en el Antiguo Régimen era costumbre realizar (Rivasplata, 2014a, pp. 81-118). La madre mayor era la responsable interna del manejo del hospital y como era uno femenino, prácticamente se ocupaba de su total gestión. Este cargo existía 
en muchos hospitales castellanos (Rivasplata, 2014b, pp.134-184). Uno de los deberes de la madre mayor del Pozo Santo de Sevilla era pedir a la Misericordia anualmente los tres mil reales para la provisión del trigo por cuenta de la renta corrida de uno de sus benefactores ${ }^{1}$. Otra de sus obligaciones, previo permiso de la Misericordia, era hacer las reformas internas que necesitara el hospital.

\section{MATERIAL Y MÉTODO}

Este estudio es histórico descriptivo. La recogida de información se ha realizado a través de fuentes primarias y secundarias. Entre las fuentes primarias hemos utilizado la documentación archivística proveniente del Archivo Histórico Provincial de Sevilla (AHPSse) y del Archivo de la Diputación Provincial de Sevilla (ADPSse). En el primer archivo se encuentra documentación del hospital de la Misericordia y en el segundo del hospital del Pozo Santo. En cuanto a las fuentes secundarias se ha recurrido a libros y documentos escritos provenientes de los archivos mencionados así como del fondo histórico de la Universidad de Sevilla.

\section{DESARROLLO DEL TEMA}

La Casa Pía de la Misericordia y la madres mayores Beatriz de la Concepción (16841686) e Isabel de San Francisco del Hospital del Pozo Santo (1686-1706)

Las fuentes del Archivo Histórico Provincial de Sevilla indican que la Casa Pía de la Misericordia gestionaba y administraba al hospital del Pozo Santo desde 1684. Aquel año, el diputado nombrado por la Misericordia para controlar al Pozo Santo don Esteban Arpe dio cuenta que la madre mayor Beatriz de la Concepción le había participado que tenía dos mil pesos que le había dado de limosna la viuda de don Ignacio Mongabur, doña María Carrillo, para que se impusiese en renta lo redituable y sirviese para la dote de una cama de las incurables del mencionado hospital. La madre mayor quería hacer este deseo realidad. El cabildo ordenó que el tesorero recibiese el dinero del arca de empleos y diese carta de pago de la mencionada cantidad, bajo el cuidado de los diputados don Luis Federique y don Esteban Arpe y que se ocuparan de que se cumpliese y diesen cuenta al cabildo de todo ${ }^{2}$. Dotar a una cama de incurables significaba atender a un enfermo gratuitamente, pues se le subvencionaba los gastos generados con la renta que el dinero donado generase anualmente. Esta era una costumbre pía bastante arraigada en el Antiguo Régimen (Rivasplata, 2015, pp. 243272).

Otro de los deberes de la Misericordia era nombrar al capellán, a la madre mayor y a la madre ayudante. En 1686, el padre mayor indicó en el cabildo de la Misericordia que era necesario nombrar capellán que asistiera en los ejercicios necesarios para administrar los sacramentos a las enfermas del Hospital del Santo Cristo de los Dolores y ayudarles a bien morir, tener los libros al día y cumplir con las demás obligaciones que disponía la regla del hospital. El nuevo capellán mayor nombrado fue Francisco de los Ríos ${ }^{3}$. Asimismo, aquel año, la madre mayor era Beatriz de la Concepción, pero le había dado perlesía y ya no mejoraría, por lo cual fue necesario hacer elección de una nueva autoridad femenina que gobernara el hospital y a las demás ma-

\footnotetext{
${ }^{1}$ AHPSse, Libro cabildo 4757(1719-1723) 10/06/1723

${ }^{2}$ AHPSse, Libro cabildo 4753, 12/11/1684, f. 33v

${ }^{3}$ AHPSse, Libro cabildo 4753, 04/08/1686, f.118v.
} 
dres auxiliares. El cabildo de la Misericordia ordenó que el padre mayor dispusiera cuanto antes la ejecución de las elecciones para lo cual llamaría a las juntas y cabildos extraordinarios que fuesen necesarios para el complimiento de aquella obligación ${ }^{4}$.

Todo acontecimiento que pudiese alterar la cotidianidad en el Pozo Santo tenía que comunicarse a la Casa Pía de la Misericordia. Una comisión era nombrada al iniciar el año para examinar cualquier asunto que sucediese en el Pozo Santo e emitiera un informe para que el cabildo tomase una decisión. En 1688, la madre mayor Isabel de San Francisco pidió licencia para tomar un corral para las oficinas del hospital y se remitió a la comisión un informe de los diputados y del maestro mayor ${ }^{5}$. Cinco meses más tarde, la misma madre mayor solicitó permiso para tomar asiento del sitio y solar de la universidad de beneficiados de la ciudad de Sevilla, pues era necesario ampliar el espacio ocupado para la panadería. Solicitud que se remitió a los diputados elegidos para estudiar la situación ${ }^{6}$. Una vez construido los nuevos lavaderos y demás oficinas, se procedió a terminar de hacer la tahona y el horno en la casa corral que tomaron de la universidad de beneficiados en 1689. La construcción costó 500 pesos de a diez reales de plata, obtenidas de las arcas del hospital, dando cuenta de lo gastado 7 . Ya para febrero de 1690, la obra del almacén, panadería, demás aposentos y oficinas del hospital del Santo Cristo de los Dolores habían sido acabadas, gastando14 mil reales ${ }^{8}$.

Nueve años más tarde, en 1699, la ampliación del Pozo Santo continuó gracias a la tenaz voluntad de su madre mayor Isabel de San Francisco quien sugirió a su patrono, la Misericordia, tomar dos casas, una de la fábrica de la parroquia de San Ildefonso a tributo perpetuo y otra del hospital del Espíritu Santo en calle los Colcheros, haciendo permuta y cambio con otra casa que tenía el hospital de los Dolores en la calle de los Lombardos. La madre pidió la licencia a la Misericordia, como a patrono para ejecutarlo y que se nombrara un hermano de esta casa para perfeccionar el ajuste y que se otorgara las escrituras que conviniese con la mayor seguridad. El cabildo cometió este negocio a Juan de Molina9 .

De esta manera, se observa que la intervención de la madre mayor Isabel de San Francisco en la vida del Pozo Santo fue determinante. La Misericordia aceptaba sus sugerencias antes que del mismo capellán e incluso intermediaba si éste tenía alguna necesidad. Así, en 1700, la madre mayor pidió al cabildo a través de su representante, es decir uno de los diputados elegidos para mediar los asuntos del Pozo Santo, que permitiera que el capellán de la Misericordia, Francisco de Castro, continuara asistiendo a los enfermos en sus necesidades espirituales que ya lo estaba haciendo desde la petición de la anterior madre mayor en 1686.

"Habiendo dado cuenta el Sr Don Fernando Caballero, núm. 25, hermano y diputado del hospital del Santo Cristo de los Dolores de esta Santa Casa que es patrona de la pretensión que tiene la madre Isabel de San Francisco, madre mayor del dicho hospital sobre que se le de licencia por este cabildo para asis-

\footnotetext{
${ }^{4}$ AHPSse, Libro cabildo 4753, 07/07/1686, f.115v. ${ }^{5}$ AHPSse, Libro cabildo 4753, 07/03/1688, f.183r. ${ }^{6}$ AHPSse, Libro cabildo 4753, 08/08/1688, f.196v. ${ }^{7}$ AHPSse, Libro cabildo 4753, 13/08/1689, f.240v ${ }^{8}$ AHPSse, Libro cabildo 4753, 11/02/1690, f.257r. ${ }^{9}$ AHPSse, Libro cabildo 4754, 04/04/1699, f. 350r.
} 
tir de noche a las necesidades espirituales de sus enfermas a don Francisco de Castro y Arroyo, capellán mayor de esta santa casa con retención de su plaza cuya pretensión consiguió la madre Beatriz de la Concepción, madre mayor que fue por petición que dio en el cabildo general de 3 de marzo de 1686, y habiéndose conferido sobre todo se acordó de conformidad se observe y guarde lo que paso en dicho cabildo de 3 de marzo en que habiéndose votado por la mayor parte de votos que por entonces y sin que sirva de ejemplar para otro ningún capellán mayor se le permita al dicho don Francisco y no a otro ninguno a dicha asistencia y por no haberse puesto en ejecución se le hace la misma gracia arreglándose la dicha determinación”. ${ }^{10}$

La preocupación principal del Pozo Santo era la escasez de dinero para su manutención. Por aquella razón, la madre mayor Isabel de San Francisco propuso fundar una hermandad de señoras para fomento del hospital. La idea fue debatida y votada en el cabildo de la $\mathrm{Mi}$ sericordia, habiendo salido la mayor parte el voto positivo. De esta manera, el cabildo acordó dar licencia a la madre mayor para hacerlo en $1700 .^{11}$

El Pozo Santo recibía donaciones testamentarias que le permitían continuar su obra pía. Una de las más generosas dadas en el siglo XVII correspondió del capitán Miguel de Benavides que dejó sus bienes para que lo administrara la Misericordia y pudiese con las

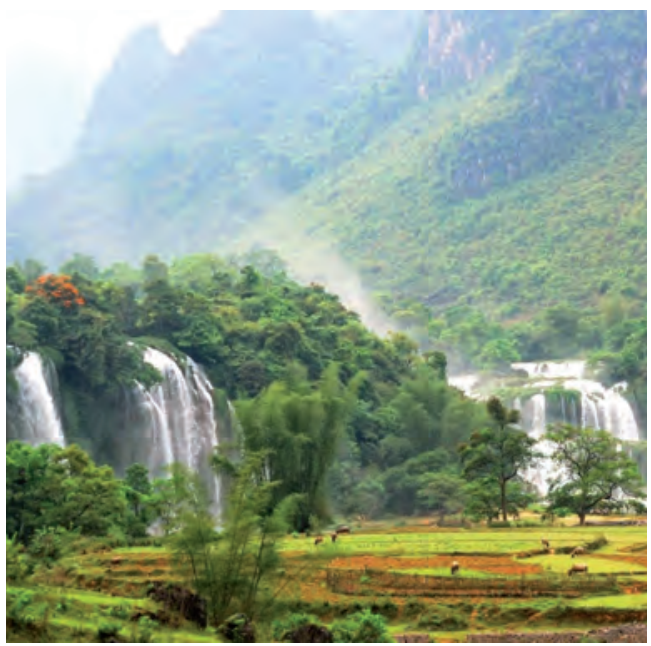

rentas dotar a hidalgas para tomar velo negro en los conventos. También mandó que la mitad del residuo de la dotación que creó fuese entregada al hospital del Pozo Santo. Esto lo sabía la madre Isabel de San Francisco desde hacía años y al ver que no se concretaba, pidió en 1703 se le mandase pagar la porción que se le debiera. El cabildo de la Misericordia encargó esta tarea a la junta de hacienda, previo informe de la contaduría ${ }^{12}$. También aquel año, el padre prior del monasterio de San Jerónimo indicaba que el hospital del Pozo Santo del que era patrono la Misericordia tenía un haz de tierras que lindaba con sus olivares pidió se le permutara con alguna de las casas que tenía su convento. El cabildo de la Misericordia no lo aceptó. ${ }^{13}$

Todos los años, la madre mayor tenía que solicitar a su patrona, la Misericordia, para que le entregara el dinero que los donadores le dejaban a través de testamento. Se trataba de una formalidad. Por ejemplo, en 1704, la ma-

\footnotetext{
${ }^{10}$ AHPSse, Libro cabildo 4755, 01/08/1700, f.17v 
dre mayor Isabel de San Francisco pidió que en atención a las grandes necesidades que tenían sus enfermas por las cortas limosnas que se le hacían, le mandara socorrer la Misericordia con las dotaciones que administraba o del residuo del capitán Miguel de Benavides, pues su mitad pertenecía al Pozo Santo. El padre mayor y los hermanos de la Misericordia acordaron que la contaduría ajustara la cuenta para que ejecutara lo pedido ${ }^{14}$. Al cabo de dos años, esta madre mayor enfermó y el 5 de junio de 1706, el padre mayor comunicó al cabildo de la Misericordia que aquella madre estaba "postrada e inhábil, sin poder continuar en el empleo". No dejó el cargo por fallecimiento sino por enfermedad. Ocupó una cama de incurables hasta su fallecimiento. Esta madre mayor ejerció el cargo por veinte años desde 1686.

\section{La Casa Pía de la Misericordia y la madre mayor Ana de San Bernardo (1706-1714)}

El nombramiento de una nueva madre mayor se aproximaba según disponía la regla del hospital en el capítulo 10. Cuatro hermanas serían propuestas, dos por el capellán, otra por la madre mayor que dejaba de ser o la madre más antigua. Otra propuesta provendría de la madre ayudante ${ }^{15}$.

La votación fue la siguiente: el capellán del hospital del Pozo Santo eligió a Ana de San Bernardo y a la hermana ayudante fue Jerónima Juan de Santa Teresa. La hermana más antigua, la madre Rosalia María eligió a la madre Ana de San Bernardo. También, todos los mencionados eligieron a la madre ayudante. Finalmente, se acordó de conformidad proponer al cabildo a Ana de San Bernardo como madre mayor y Jerónima Juana de Santa Teresa para ayudante de madre mayor ${ }^{16}$. El día siguiente el cabildo aprobó la elección ${ }^{17}$.

En aquel año de 1706, el Pozo Santo recibió una importante donación hereditaria. El padre mayor comunicó que había fallecido don Juan Francisco Gómez y había dejado en su testamento por heredero al hospital beaterio de mujeres de Santo Cristo de los Dolores junto al Pozo Santo y por patrono y administrador a la Misericordia tres fiestas que dejaba dispuesto se celebraran en los días de la "Purísima Concepción de Nuestra Señora, San Joseph y San Juan Bautista" y que se impusiera lo necesario para ellas del caudal que dejaba a la Misericordia. La distribución del residuo se convertiría en obras pías dirigida a pobres y personas que asistían en el hospital. El cabildo después de leer las cláusulas del testamento, aceptó el patronato. La Misericordia como patrono y administrador del hospital del Santo Cristo de los Dolores aceptó la herencia con beneficio de la ley del inventario "en todo por todo según y cómo se contiene en las cláusulas de testamento que pasó ante Pedro Luis de Vargas secretario público de Sevilla el 22 de junio de 1706 ". 18

Respecto a este testamento, el padre mayor indicó que en el mencionado documento había unos bienes muebles inventariados que se debían entregar a las madres del beaterio para que los usaran a su arbitrio, sus menesteres y

\footnotetext{
${ }^{14}$ AHPSse, Libro cabildo 4755, 06/04/1704,s/f.

${ }^{15}$ ADPS. Legajo 1. Acuerdos del cabildo de la Casa de la Misericordia, referentes a los nombramientos de la madre mayor y madre ayudante del hospital, (1714. 1748, XIX), s/f. ADPS. Acuerdos del cabildo de la casa de la Misericordia referente a los nombramientos del Capellán Mayor del hospital (1718-1797), s/f.

${ }^{16}$ AHPSse, Libro cabildo 4755, 05/06/1706,s/f.

${ }^{17}$ AHPSse, Libro cabildo 4755, 06/06/1706,s/f. Eligieron el capellán del hospital, la madre ayudante, la hermana más antigua se aprobó la elección.

${ }^{18}$ AHPSse, Libro cabildo 4755, 04/07/1706,s/f.
} 
en lo que tocaba a papeles y títulos se entregarían a la contaduría. En cuanto la factura de las alhajas empeñadas y géneros que el difunto envió a Indias se entregarían al tesorero y que se otorgaría carta de pago por el cabildo dando la orden a Joan Cid de cómo había de hacerse. Se necesitaba de persona que corriese con la administración de la renta del hospital por lo que se nombró a don Agustín de Valderrama a quien se le dio poder para la percepción y cobranza para que lo entregase a las madres para su manutención, tomando recibo de ellas. Este administrador recibiría por este trabajo cinco por ciento por su cobranza. ${ }^{19}$

La nueva madre mayor sugirió comprar un órgano para evitar el gasto de alquilar uno varias veces al año que sería como tener un tributo perpetuo. El Pozo Santo no tenía órgano y alquilaba uno por 20 reales cada vez que lo necesitaba para las fiestas religiosas. La dotación de don Juan Francisco Gómez exigía la realización de tres eventos cada año. En aquel entonces, un realejo de buena calidad estaba siendo ofertado a 100 ducados al contado, lo que valdría 200 ducados. La madre mayor Ana de San Bernardo lo comunico a su patrona, la Misericordia, para que decidiera lo que conviniese. El cabildo mandó a los diputados para que realizaran la compra del realejo con el dinero del mismo testador al que iban dirigidas las fiestas. Se prohibió adquirirlo a través de un préstamo, para evitar endeudamientos..$^{20}$

Entretanto, la antigua madre mayor Isabel de San Francisco falleció. La Misericordia entregó 500 reales para su entierro, cubierto la mitad de la dotación del capitán Benavides, a petición de la nueva madre Ana de San Bernardo. Como se observa, prácticamente, toda sugerencia dada por las madres mayores del Pozo Santo era aceptada por la Misericordia ${ }^{21}$. Las responsables femeninas del beaterio estudiado solían tomar la iniciativa para solucionar sus premuras económicas e incluso, a veces, solo comunicaban a la Misericordia lo que ya habían realizado. Así, la nueva madre mayor había ido a ver al arzobispo de Sevilla ante la estrechez económica del Pozo Santo, para suplicarle licencia para salir a las calles sevillanas a pedir limosna para cubrir la manutención del Pozo Santo ${ }^{22}$. Una vez que la madre mayor obtuvo el permiso del arzobispo, se lo comunicó al cabildo de la Misericordia. Y “visto la licencia que se da se acordó de conformidad conformarse con ella." ${ }^{23}$

\section{La Casa Pía de la Misericordia y la ma- dre mayor Jerónima Juana de Santa Teresa (1714-1726)}

El Pozo Santo estaba conformado por 34 madres y sirvientas, 7 sirvientes, 46 enfermas

\footnotetext{
${ }^{19}$ AHPSse, Libro cabildo 4755, 30/07/1706, s/f.

${ }^{20}$ AHPSse, Libro cabildo 4755(1700-1706) 05/09/1706,

${ }^{21}$ AHPSse, Libro cabildo 4755(1700-1706) 17/10/1706. En 1706, “viose una petición de la madre Ana de San Bernardo madre mayor del hospital del Santo Cristo de los Dolores diciendo haberse llevado nuestro señor para sí a la madre mayor Isabel de San Francisco que fue del hospital, pidiendo que dé la mitad del residuo de la dotación del capitán Miguel de Benavides que pertenece a dicho hospital se le socorrió para el entierro de la susodicha y habiéndose conferido se acordó de conformidad se diesen 500 reales para este fin y que la contaduría aplicara de los primeros que perteneciere y hubiere de haber dicho hospital".

${ }^{22}$ ADPSse, Licencias dadas al hospital para pedir limosnas, 1674-1713, legajo 1, s/f.

${ }^{23}$ AHPSse, Libro cabildo 4755(1700-1706) 05/02/1707, s/f. En 1707, "Petición de la madre mayor del hospital del Pozo Santo había ocurrido al arzobispo de esta ciudad representándole la estrechez que padecía el hospital suplicándole diese licencia para tener demandante que pudiese salir para que pudiese salir a pedir y solicitar limosnas para su manutención y que se le había concedido de que las madres daban cuenta al cabildo y habiéndose conferido y visto la licencia que se da se acordó de conformidad conformarse con ella."
} 
en cama, de las cuales 8 estaban dotadas. En total había 87 personas en $1715^{24}$. El Pozo Santo solía endeudarse para mantenerse y le prestaban personas conocidas, pero para que otra vez le diera, tenía primero que devolver lo que le había prestado. Aquel año, la madre Jerónima Juana de Santa Teresa del Pozo Santo indicó el hospital gastaba mucho para el sustento de las madres y sirvientes pobres quienes superaban la cantidad de 100 personas. También el Pozo Santo gastaba mucho en ropa y vestuario que había llevado a la madre a empeñarse en más de 40 reales que le habían prestado diferentes personas. La urgencia de comprar trigo, llevó a pedir dinero a la Misericordia que mandó dar 200 reales del residuo del legado de Juan Francisco Gómez. ${ }^{25}$

En 1716 se volvió a elegir a las mismas personas que ocuparon los puestos de madre mayor y ayudante, es decir a Juana de Santa Teresa y Flora Francisca de San Antonio, respectivamente. Esta decisión se tomó como respuesta a los memoriales que se leyeron en la Misericordia enviadas por el capellán del Pozo Santo Francisco de Castro y Arroyo y otros miembros, apoyando la buena gestión de las mencionadas mujeres. ${ }^{26}$ La madre mayor Juana de Santa Teresa se mantuvo por muchos años en el cargo. En 1719, puso al corriente que había sido preciso hacer 113 varas de cañería que había tenido un costo de 1.200 reales y para que se saldara la deuda, hallándose el hospital con falta de medios, solicitaba que la Misericordia lo pagara con el dinero producto de los réditos que el donador Juan Estaban de
Ollo había dejado para que lo empleara el Pozo Santo después del ajuste de cuentas realizado con los herederos de un tributo. ${ }^{27}$

La ampliación del Pozo continuó a mediados del XVIII porque su patrono, la Misericordia, había comprado la casa contigua a su iglesia que había pertenecido a las monjas de San Clemente. ${ }^{28}$ En 1726, el padre mayor aviso que la madre mayor Juana de Santa Teresa del Pozo Santo había muerto después de 12 años ejerciendo el cargo.

\section{La Casa Pía de la Misericordia y la ma- dre mayor Flora Francisca de San Antonio (1726-1737)}

En el cabildo se propuso a su reemplazan$t^{29}$. La elegida fue Flora Francisca de San Antonio al cabo de un mes recibió 400 ducados para el suministro de trigo anual, facturada del caudal que estaba en las arcas de empleos de la Misericordia del legado que dejó el secretario Sebastián de Santamaría. También recibió 600 reales para el entierro de la anterior madre mayor. La madre ayudante elegida fue Isabel de San Francisco. ${ }^{30}$

En 1728, el Pozo Santo tenía 90 personas entre enfermas, hermanas y sirvientes. La madre mayor sugirió por ser su renta corta y la necesidad muy grande, viviendo con carencias, le parecía preciso que igual que la hermandad de la Caridad se debía nombrar diputación en el hospital del Pozo Santo para que se pidiese limosna para trigo y otras cosas para su sustento. ${ }^{31}$ En 1728, Flora Francisca fue reelegida como madre mayor. ${ }^{32}$ Ejerció el cargo por 11

\footnotetext{
${ }^{24}$ AHPSse, Libro cabildo 4756(1715-1718) 18/07/1715.

${ }^{25}$ AHPSse, Libro cabildo 4756(1715-1718) 07/07/1715

${ }^{26}$ AHPSse, Libro cabildo 4756(1715-1718) 8/08/1716.

${ }^{27}$ AHPSse, Libro cabildo 4757(1719-1723) 03/09/1719. s/f

${ }^{28}$ AHPSse, Libro cabildo 4758(1723-1727) 12/01/1726

${ }^{29}$ AHPSse, Libro cabildo 4758(1723-1727) 06/07/1726

${ }^{30}$ AHPSse, Libro cabildo 4758(1723-1727) 07/07/1726

${ }^{31}$ AHPSse, Libro cabildo 4759(1727-1732) 11/04/1628, s/f.

${ }^{32}$ AHPSse, Libro cabildo 4759(1727-1732) 1/08/1628, s/f.
} 
años. Al mes se nombró como madre ayudanta a Feliciana de Santa Teresa quien en 1737 se convirtió en madre mayor. ${ }^{33}$

\section{El primer problema de consideración que} provocó el despido de la madre mayor Feliciana de Santa Teresa y del capellán del Pozo Santo a pedido del provisor que acató la Hermandad de la Misericordia(1737)

El 3 de agosto de 1738, la madre mayor Felisiana de Sta. Teresa había realizado una petición en la que dijo necesitaba hacer suministro de 400 fanegas de trigo para el año y que aunque había hecho muchas diligencias sólo había podido juntar 7 fanegas de limosna, por lo cual se dirigió al arzobispado de Sevilla, logrando hablar con el arzobispo a quien manifestó que no tenía dinero para comprar el trigo. Al final lo cubrió el hospital del dinero que tenía en las arcas para pagar a los que trabajaban en la Misericordia. Acto frecuentemente practicado el prestarse dinero de otras obras pías para mantener a otras. ${ }^{34}$

El 16 de octubre de 1738, la madre mayor comunicó al cabildo de la Misericordia que era patrono administrador no tener bastante dinero para el abastecimiento de trigo. No fueron suficientes los 4.015 reales que quedaron líquidos del medio año de 1737 de la pensión que pagaba el arzobispo cuya libranza se le había entregado con acuerdo del cabildo general de 3 de agosto de 1738 para que la cobrase, ni tampoco con los 20.001 reales que por acuerdo del cabildo de 7 de septiembre de ese año se le libraron por cuenta de las rentas del mencionado hospital, además de que aquella libranza no se había podido cobrar. La madre mayor solicitaba con el arzobispo le mandase pagar y siendo precisas 400 fanegas de trigo era corta la mencionada cantidad por lo cual solicitó al cabildo que diese algún dinero perteneciente al Pozo Santo o lo que el cabildo tuviese por más conveniente le mandase despachar para la referida provisión de trigo. Este pedido de la madre mayor no fue atendido. ${ }^{35}$

Ese mismo día, el padre mayor propuso que era necesario que tuviesen voto resolutivo los diputados de la junta para las cosas relativas al hospital del Pozo Santo sobre todo en los casos graves. Sin embargo en su creación se les dio voto consultivo, por lo que los hermanos decidieron realizar un cabildo extraordinario para deliberar el asunto. Otros puntos a tratar eran arrendar o vender la hacienda de campo que tenía el Pozo Santo por considerar algunos no ser útil su administración y que se le diese otro uso. Los hermanos eligieron entre ellos a dos diputados con capacidad de reformar y arreglar lo que les pareciera en el asunto encomendado. El cabildo les encargó a los diputados del Pozo Santo estudiar la mejor decisión en cuento a la venta o arriendo de la hacienda y la reforma necesaria en la panadería del beaterio. ${ }^{36}$ Sin embargo a los pocos días, la madre mayor Feliciana Teresa de Santa Teresa y las demás madres del hospital volvieron a pedir dinero para el trigo que necesitaban a pesar que la Misericordia había rechazado este pedido.

\footnotetext{
${ }^{33}$ AHPSse, Libro cabildo 4759(1727-1732) 14/09/1628, s/f; AHPS, Libro cabildo) 4761(1736-1741) 27/01/1737, f.11r.

${ }^{34}$ AHPSse, Libro cabildo 4761(1736-1741) 08/09/1738. El 21 de mayo de 1737 había hecho esta junta por provisión del cabildo en que se propuso que para tomar satisfacción de 110 reales que la Misericordia le había suplido del caudal de arcas corrientes se le descontasen en el tiempo de 4 años de las rentas que se le administraran de juros y tributos y que de lo demás que de ella sobrase lo recibiese el Pozo Santo para su mantención además de las rentas que estaban a cargo de Agustín de Valderrama ,su receptor, y las limosnas y demás efectos que le pertenecen lo que se aprobó en el cabildo de 7 de abril de 1737. ${ }^{35}$ AHPSse, Libro cabildo 4761(1736-1741) 16/10/1738

${ }^{36}$ AHPSse, Libro cabildo) 4761(1736-1741) 16/10/1738
} 
"Viose un memorial de la madre mayor Feliciana Teresa de Santa Teresa y de las demás madres del hospital de que este cabildo es patrono administrador en que dicen que por los señores padre mayor y diputados de dicho hospital se les hizo saber lo acordado en el cabildo del 5 próximo pasado y hallándose con diferentes reparos sobre los puntos que contiene y no siendo tan fáciles dar entero cumplimiento de ellos por necesitarse de consulta y no poderse dar prontamente pues se necesita de tiempo dilatado para la referida consulta suplicaron a este cabildo se sirviese suspender el referido acuerdo quedando por ahora obedientes a sus mandatos sin perjuicio del derecho que a dicho hospital puede pertenecer por su regla y fundación. Y asimismo suplicaron que mediante estar manteniéndose con bacalao no teniendo trigo y necesitando de diferentes provisiones como lo manifestaron a esta cabildo, si de presente hubiese algún caudal de las rentas de dicho hospital o de lo que este cabildo tuviese por conveniente se les entregase y habiéndose conferido se acordó de conformidad se guarde lo acordado y este memorial se remite a la junta que está formada para lo tocante a dicho hospital para que se ejecute lo que le pareciese en orden a la necesidad que representa dicho hospital". ${ }^{37}$

Al cabo de un mes, el provisor había enviado a la Misericordia un dictamen escrito el 15 de diciembre de 1638 que se leyó en el cabildo de la casa pía sobre convenir sin dilación el despedir al capellán del Pozo Santo y nombrar a otro, como también otra madre mayor y ayudantes para que hubiese la paz que se deseaba y se pusiese en orden lo demás que fuese conveniente, dispensando por esta vez la formalidad que para ello exigía la regla del hospital, pues así lo tuvo por conveniente después del escrutinio y visita que hizo al beaterio el día 14 de diciembre. El provisor sugirió a una de las madres como madre mayor, aunque sabía que la hermandad de la Misericordia nombraría la que le pareciese.

Al día siguiente, el 16 de diciembre de 1738, se realizó el cabildo extraordinario en la Misericordia en donde fueron nombrados como diputados el conde del Águila y el conde de Mejorada para que investigaran que pasaba en el Pozo Santo e informaran al cabildo para tomar una decisión.

"En 1638, en vista de todo lo que se ha expuesto por escrito y de palabras en este cabildo tocante a dependencia del hospital del Pozo Santo de que es patrono administrador se acordó de conformidad el nombrar a el sr. Conde del Águila para que con el de Mejorada ejecuten lo que llevan entendido y que dé resulta de su comisión se aboquen con el sr. arcediano de Sevilla para que practique su comisión y el manifiesto que se ha extendido para el sr. arzobispo se comete a el sr. Alonso de los Ríos para que lo proporción de acuerdo con el contador mayor según la postura que ha tomado el negocio de que se trató en este cabildo" ${ }^{38}$

La investigación llevó al cabildo de la Misericordia a despedir al capellán y a la madre

\footnotetext{
${ }^{37}$ AHPSse, Libro cabildo 4761(1736-1741) 31/10/1738

${ }^{38}$ AHPSse, Libro cabildo 4761(1736-1741) 16/12/1738 cabildo extraordinario.
} 
mayor porque estaban exigiendo dinero para comprar trigo que no alcanzaba en el Pozo Santo, incluso fueron a ver al arzobispo de Sevilla y al Provisor para manifestarles las razones por las que la hermandad de la Misericordia había tenido para mudar de gobierno en diferentes cosas tocantes al hospital del Pozo Santo del que era patrono administrador. Los diputados lograron informar verbalmente solo al provisor, mas no al arzobispo por encontrarse fuera de Sevilla, sin embargo supieron que estaba enterado de lo que pasaba. El provisor indicó que permitía en su nombre y en el del arzobispo que la Misericordia, como patrono que era del Pozo Santo, aplicara las correcciones que creyera oportunas

El padre mayor formó cabildo extraordinario en el que se volvió a leer el papel del provisor, opinando los hermanos sobre el tema. El cabildo aceptó la dispensa de la regla que el provisor le concedió por esta vez para el nombramiento de la madre mayor y ayudante y cambiar al capellán, conformándose con el dictamen del mencionado inspector. El cabildo escuchó a los diputados de lo que había pasado con el provisor en cuanto a las novedades que se habían ocasionado por la madre mayor y capellán del hospital del Pozo y la forma que gestionaban y cuya consecuencia había creado perjuicio al hospital en cuanto a su régimen $y$ buen gobierno, asistencia y cuidado de las enfermas en cuanto a la superfluidad con que se había procedido y otros daños irreparables que la hermandad y el provisor habían reparado, inclinándose a que no había otra solución que cambiar a las cabezas.

"El motivo del despido fueron las novedades que habían ocasionado la madre mayor y el capellán del hospital de que la en el modo y forma que practicaban que había ocasionado daño y perjuicio al hospital, en su régimen $y$ buen gobierno asistencia y cuidado de las enfermas y superfluidad con que se había procedido y otros daños irreparables que así por esta hermandad como por dicho sr. provisor se han reparado". 39

El capellán Isidoro de Rivera fue despedido en adlibitum et adnutum porque fue nombrado por el tiempo que quisiera la hermandad y también por el veredicto proveniente de la visita y escrutinio que el provisor personalmente realizó formalmente en el Pozo Santo. Prohibiéndole que bajo ningún pretexto pudiese incluirse en la iglesia ni en el hospital ni en la hacienda de campo que tenía. Obligándosele que cumpliera lo mandado, dejando el cuarto que ocupaba. Mientras tanto el cargo lo ocupó un sacerdote que eligió el padre mayor hasta que el cabildo en pleno nombrara a otro capellán. Por las mismas razones expuestas, la madre mayor Teresa fue separada del cargo, no pudiendo ejercerlo nunca más ni siquiera el de ayudante. El cabildo siguió el consejo del provisor, eligiendo a la madre Antigua por madre mayor y en la misma forma por madre ayudante a la madre Concepción. El padre mayor y el secretario les comunicaron la decisión para su aceptación y a todas las demás hermanas para que las consideraran madre mayor y ayudante para que las obedecieran en todo. Ambas madres nombradas tomarían las llaves de todos los cuartos del hospital, así como de la despensa para hacer las distribuciones del caso.

Una vez terminado el cabildo extraordinario, el padre mayor don Luis de Castilla y Guzmán acompañado del Conde de Villlanueva, el

${ }^{39}$ AHPSse, Libro cabildo 4761(1736-1741) 19/12/1738. 
marqués de Vallehermoso, Francisco de Paiva Torres, conde del Águila, conde de Mejorada y de Francisco de Villasis y el secretario de la Misericordia fueron al Pozo Santo. Reunidos todos los mencionados además del capellán del hospital, la madre mayor, la ayudante y la mayor parte de las demás hermanas en la sala principal del Pozo, se leyeron los acuerdos tomados en el mencionado cabildo el que se despedía al capellán, se suspendía de sus cargos a la madre mayor y ayudante. Mientras se eligiera a la nueva madre mayor, se eligió a la madre Antigua y a la madre Concepción por su ayudante.

Al cabo de algunos días, el contador de la Misericordia realizó un informe que en virtud de lo acordado en el cabildo general del 1 de febrero de1739, se pusieron edictos por 15 días, llamando a los parientes hacedores y confesores para nombrar al capellán de misas que en el hospital del Pozo fundó Ana de Trujillo y habiéndose cumplido el termino no había acudido pariente alguno y sólo Felipe Ponce y Figueroa, cura de la iglesia de San Andrés y capellán mayor del hospital, pretendiendo que se le nombrara. Entrego memorial y el cabildo acordó nombrarlo el 4 de enero de $1739 .^{40}$

La actitud del nuevo capellán era de completa supeditación a la Misericordia, no tomando resolución alguna sin antes consultarle. Felipe Ponce y Figueroa, preguntó si se habían de cumplir las memorias que tenía obligación el hospital del Pozo, proveniente de las diferentes memorias de misas cantadas y rezadas de que presentó nómina y que habiéndose dejado de celebrar como la del día de la Purísima Concepción y estando próxima la que tocaba que era el día de San José, no habiendo en el hospital cómo satisfacer sus costos avisaba al cabildo si se iba a cumplir con aquella memoria. ${ }^{41}$

La administración del Pozo Santo después de la remoción de las autoridades de sus autoridades por la Misericordia ( 1739- 1745 ) durante la gestión de la madre mayor María de la Antigua

La Misericordia tenía que tomar las resoluciones y no la madre mayor ni el capellán como antiguamente se hacía. Así que el cabildo determinó que en casos de urgencia la Misericordia prestaría al Pozo Santo 10000 y 2000 reales, proveniente de las arcas corrientes, pero esta cantidad ya se había comprobado que no era suficiente para cubrir los gastos en trigo, carne, aceite, legumbres, gastos menudos y manutención de las enfermas, de la madre y hermanas que asistían y del culto llevado a cabo por el capellán mayor.

Según la contaduría, el Pozo tenía una renta corriente de un juro del que recibía una pensión 1000 reales que le pagaba la dignidad arzobispal, pero las demoras de la cobranza como era habitual en toda renta, provocaba retrasos en su cobranza. La consecuencia inmediata era la necesidad de un suplemento y adelanto que en ocasiones podía subir de los 2000 reales, otorgada por la Misericordia. El cabildo llevaba cuenta y razón de todos los gastos efectuados y del estado del Pozo a través de los recibos de la madre mayor, firmados por los diputados de la comisión. De esta manera, el cabildo llevaba las cuentas y sabía el estado del Pozo Santo anualmente. ${ }^{42}$

\footnotetext{
${ }^{40}$ AHPSse, Libro cabildo 4761(1736-1741) 04/01/1739. Giménez Muñoz, María Carmen (2006) "Breve historia de los establecimientos benéficos de Sevilla desde su fundación hasta 1900”, en Hispania Nova. Revista de Historia Contemporánea, núm. 6. Sevilla, Universidad-Departamento de Historia Contemporánea, 2006, p.10.

${ }^{42}$ AHPSse, Libro cabildo 4761(1736-1741) 01/03/1739
} 
En 1739, el padre mayor dio cuenta que la madre mayor suspendida de ejercer algún cargo en el Pozo llamada Feliciana Teresa de Santa Teresa por acuerdo del cabildo extraordinario del 19 de diciembre del 1738 era de las más antiguas del hospital, habiéndose retirado en el interior de él, ejerciendo los oficios más humildes y que estaba arrepentida de su accionar. Su intención habría sido "el aumentarlo y solicitar sus alivios" y que "lo que hubiese faltado, nació de ignorancia, lo noticiaba todo dicho ser". El cabildo acordó de conformidad que la madre Santa Teresa quedara apta para poder ejercer el empleo de madre mayor y el de ayudante, siempre que este cabildo le nombrara a ello, sin que sirviera de impedimento el haberla suspendido por el citado acuerdo. Incluso, el cabildo devolvió la buena opinión y fama que tenía antes. ${ }^{43}$

El cabildo extraordinario del 19 de diciembre de 1738 había prohibido que el Pozo lavara la ropa de la iglesia y de sacristía de la Misericordia, pero se volvió a hacer al año siguiente. Así, en 1739, el padre mayor dio cuenta de que la madre mayor le había hablado repetidas veces al cabildo de la Misericordia para que la mencionada ropa se volviese a lavar en él como antes se hacía lo que se comunicó al cabildo para que lo determinase. La ropa de la iglesia sería llevada al Pozo por el atento aseo con que lo hacían las madres. ${ }^{44}$

En 1740, el cabildo aplicó lo acordado en el cabildo del 1 de marzo de 1739 de que todo lo que procediese de las rentas pertenecientes al hospital del Pozo, incluso la pensión y lo que sobrase de la hacienda de campo, entrase en poder de su receptor don Agustín de Valderrama que daría cuenta de lo que hubiese cobrado anualmente y que en el ínterin fuese supliendo de los caudales de la Misericordia. ${ }^{45}$

El capellán mayor había realizado diferentes memorias que ascendía a la suma de 204 reales que no fueron pagadas por el Pozo Santo y no tenía como pagarlos por la brevedad de la limosna que se juntaba. La Misericordia no dio lugar a la ayuda económica que pedía. ${ }^{46} \mathrm{En}$ 1740, la madre mayor fue María de la Antigua y su ayudante Juana de la Concepción y el capellán mayor fue José de Ávalos. Sin embargo, en la elección de 1741 hubo un acontecimiento fuera de lo normal, la madre ayudante no quiso proponer a ninguna madre mayor y solo indicó que no quería ser ya más ayudante. La Misericordia la amonestó y le dijo que debía hacerlo la próxima vez y advirtió a la nueva que debía hacerlo y no concurrir en la falta de la madre Concepción. ${ }^{47}$ Aquel año, Manuela de Santa Rita fue elegida y reelegida la anterior madre mayor. ${ }^{48}$

La madre mayor pedía que se deshiciera del campo que administraba el Pozo porque en él se gastaban las limosnas y exigía una mejor administración que se asignó a una comisión de diputados de la Misericordia. En el tiempo que ejerció el cargo había experimentado lo inútil que era para el hospital el administrar la hacienda de campo que tenía, pues además de gastar en los beneficios sus frutos, gastaba cuanto adquiría de limosnas, representando otros diferentes inconvenientes por lo que

\footnotetext{
${ }^{43}$ AHPSse, Libro cabildo 4761(1736-1741) 03/05/1739, f. 199 r-v.

${ }^{44}$ AHPSse, Libro cabildo 4761(1736-1741) 03/05/1739, f. 199 v.

${ }^{45}$ AHPSse, Libro cabildo 4761(1736-1741) 03/01/1740, f. 256r.

${ }^{46}$ AHPSse, Libro cabildo 4761(1736-1741) 11/08/1740, f. 295rv

${ }^{47}$ AHPSse, Libro cabildo 4761(1736-1741) 07/01/1741, f. 336r-337v.

${ }^{48}$ AHPSse, Libro cabildo 4761(1736-1741) 07/01/1741. ADPS. Legajo 8. Donación de la Manuela de Santa Rita, madre mayor del hospital (1733-1755), n²0
} 
siendo en perjuicio de las pobres suplicó ante el cabildo dispusiese de su administración o propiedad para que administrada bien su producto sirviese de alivio al hospital. En este caso, la madre mayor exigió mejor administración de las propiedades para que el Pozo Santo satisficiera su mantenimiento. El cabildo pidió a la comisión de diputados informara la real situación en cuanto a la renta y arrendamiento de los bienes que pertenecieran al Pozo para hacérselo saber al padre mayor. ${ }^{49}$ Finalmente después de la queja el terreno fue vendido.

A pesar de las exigencias impuestas por la Madre mayor al cabildo de la Misericordia siguió en el cargo, siendo reelegida en 1743, así como su ayudante María de Santa Rita. ${ }^{50}$ En 1744, la madre María de la Antigua pidió a la Misericordia que le proveyera del aceite que necesitaba que lo solía obtener de la hacienda de campo que había pertenecido al Pozo Santo, pero que la Misericordia había vendido. El cabildo accedió. ${ }^{51}$ Como observamos la madre mayor volvió asumir el papel denunciador que siempre tuvo, necesario para la estabilidad del beaterio y que la Misericordia solía escuchar y atender.

\section{Volviendo a la normalidad, la gestión de la} madre mayor Manuela de Santa Rita(17451746), Petronila de San Francisco (17461748) y María de San Bernando (1748-1752)

En 1745, la elección de la madre mayor recayó en Manuela de Santa Rita y como su ayudan- te Petronila de San Francisco. ${ }^{52}$ En 1746, la madre mayor Manuela de Santa Rita murió el 12 de marzo de ese año y se eligió una nueva Petronila de San Francisco que había sido madre ayudante y como ayudante María de San Bernardo. ${ }^{53}$ En 1748, se nombró a la madre María de San Bernando como madre mayor ${ }^{54} \mathrm{y}$ a Petronila de San Francisco como madre ayudante. ${ }^{55}$

En 1748, la madre María de San Bernardo del Pozo dijo que le avisaron los diputados de haberse perdido la pensión de 1000 ducados que gozaba sobre las rentas del arzobispado sevillano. Esta situación afectaba gravemente a los gastos diarios del beaterio. La madre mayor estaba determinaba a ir a la corte para lograr que por intercepción del rey pudiese hacer algo por recuperar esta donación, para que no quedase el desconsuelo de no haberse realizado cuantos medios hubiesen sido posibles para recuperarlo. La madre estaba consciente que era necesario hacer varios gastos para ir a la Corte y no teniendo el Pozo Santo dinero para hacerlo, suplicó al cabildo entregarle los medios económicos para hacerlo. También pidió que el abogado Juan Trillo de la Misericordia elaborara dos memoriales uno para el rey y otro para la reina. El cabildo acordó aprobar la resolución de la madre y para facilitarlo se dio comisión al padre mayor y diputados para que discutieran lo que se necesitara gastar en el viaje. ${ }^{56}$ Logro que se volviese a donar el dinero. De esta manera la madre mayor elaboró

\footnotetext{
${ }^{49}$ AHPSse, Libro cabildo 4761(1736-1741) 05/02/1741, f. 344v. 345r

${ }^{50}$ AHPSse, Libro cabildo 4762(1741-1746) 12/01/1743

${ }^{51}$ AHPSse, Libro cabildo 4762(1741-1746) 09/02/1744. Memorial de la madre María de la Antigua, madre mayor, de que esta cabildo es patrón.

${ }^{52}$ AHPSse, Libro cabildo 4762(1741-1746) 02/01/1745

${ }^{53}$ AHPSse, Libro cabildo 4762(1741-1746) 13/04/1746

${ }^{54}$ AHPSse, Libro cabildo 4763(1746-1751) 28/04/1748, f 121r-v.

${ }^{55}$ AHPSse, Libro cabildo 4763(1746-1751) 05/05/1748, f 126r.

${ }^{56}$ AHPSse, Libro cabildo 4763(1746-1751) 29/09/1748, f 134v-135v. ADPS. Cartas dirigidas a la Madre mayor (siglos XVII y XIX), legajo 1, s/f. En el Archivo de la Diputación Provincial de Sevilla en el fondo del Pozo Santo se hallan varias cartas enviadas a las madres mayores de personas, hombres y mujeres, que estaban en Aranjuez o en Madrid con los reyes. En una de ellas relata el fallecimiento de Carlos Domingo Eusebio, hijo del futuro Carlos IV y María Luisa de Borbón-Parma el 11 de junio de 1783. El rey en aquel entonces era Carlos III.
} 
la idea y la ejecutó, cumpliendo largamente lo que se esperaba de su gestión, abogar por el Pozo Santo. Independencia plena, pues solo notificó su decisión a su patrona, la Casa de la Misericordia. En 1750, relección de madre mayor María de San Bernardo por dos años. ${ }^{57}$

\section{Los capellanes del Pozo Santo y la gestión} de la madre mayor Josepha de la Presentación (1752-1775) y Isabel del Espíritu Santo(1775-1783) (1785-1798), Isabel de San Cristóbal(1783-1785) y la madre mayor del Pozo Josefa de Santa (1798)

En 1752, el cabildo propuso a Josepha de la Presentación como madre mayor del Pozo Santo y en segundo lugar quedo Josefa de Santa Marta. ${ }^{58}$ Ambas fueron reelegidas en $1754 .{ }^{59}$ En 1756 fue nombrado contador del hospital del Pozo Santo Martin de Arrieta. ${ }^{60}$ En 1758, 1760 y 1762 el mismo dúo de mujeres fue reelegido. ${ }^{61}$ En 1760 , el padre mayor informó al cabildo que la madre mayor del Pozo Santo pidió licencia para ir a Madrid para pasar a la corte en solicitud de que continuara la pensión de mil ducados que gozaba el hospital sobre las rentas de este arzobispado que estaba para cumplir el año próximo. ${ }^{62}$

En 1764, la madre mayor del Pozo solicitó al cabildo permiso para comenzar la construcción de una enfermería y un dormitorio de co- munidad para cuyo fin se había incorporado en 1757 , la casita que hacía esquina con la calle de la Coneja. La madre mayor había conseguido del rey el valor de 13 o 14 mil reales en madera de Segura y de diferentes bienhechores de la corte y de la ciudad de Sevilla hasta 1.300 ducados. La madre mayor estaría al cargo el seguimiento del trabajo hasta su término. ${ }^{63}$

La madre Josepha de la Presentación ejerció el cargo de madre mayor desde 1752 hasta 1775 y durante su cargo incorporó al Hospital del Pozo Santo la devoción a la Virgen del Tránsito, según el capellán mayor del Pozo, José Ávalos y Urrieta. Esta madre trabajó durante estos años hasta 1770 con su ayudante José de Santa Marta. ${ }^{64}$ En 1774, trabajó junto a una nueva ayudante llamada Isabel del Espíritu Santo. ${ }^{65}$ En 1775, al fallecer la madre mayor fue Isabel la que asumió el cargo máximo con la ayuda de Isabel de San Cristóbal. ${ }^{66}$ Un envejecido capellán, Joseph de Valos y Urrieta trabajó en el hospital desde 1739 y dejó aquel cargo en 1778 en muy avanzada edad y con achaques, se le pagaba 1500 reales, y una casa contigua al hospital y postigo a su zaguán. Además tenía que cumplir una memoria de misas a 6 reales, fundada en el mismo hospital por Ana de Trujillo, aunque estuviese empeñada según tanteo. A este capellán se le jubiló y se nombró a Antonio Fontanez y Neve. ${ }^{67}$

\footnotetext{
${ }^{57}$ AHPSse, Libro cabildo 4763(1746-1751) 03/05/1750, f. 294v.

${ }^{58}$ AHPSse, Libro cabildo 4764(1751-1756) 05/05/1752 f $61 \mathrm{r}-\mathrm{v}$

${ }^{59}$ AHPSse, Libro cabildo 4764(1751-1756) 10/05/1754 f 198 r-v.

${ }^{60}$ AHPSse, Libro cabildo 4765(1756-1761) 05/12/1756 folio $1 \mathrm{v}$

${ }^{61}$ AHPSse, Libro cabildo 4765(1756-1761) 06/05/1758 folio 112v. AHPS, Libro cabildo 4765(1756-1761) 02/05/1760; AHPSse, Libro cabildo 4766(1761-1765) 08/05/1762.

${ }^{62}$ AHPS, Libro cabildo 4765(1756-1761) 20/04/1760, f. 264r. ADPS. Cartas dirigidas a la Madre mayor (siglos XVII y XIX), legajo 1, s/f.

${ }^{63}$ AHPSse, Libro cabildo 4766(1761-1765) 11/03/1764.

${ }^{64}$ AHPSse, Libro cabildo 4766(1761-1765) 05/05/1764; AHPS, Libro cabildo 4766(1761-1765) 31/05/1766; AHPSse, Libro cabildo 4767(1767-1772) 04/06/1768, f. 89 v.; AHPSse, Libro cabildo 4767(1767-1772) 16/06/1770, f. 223 r.

${ }^{65}$ AHPSse, Libro capitular de acuerdos de cabildos y juntas de la Casa Misericordia de Sevilla. 4768(1772-1778) 01/05/1774, f. $103 \mathrm{r}-\mathrm{v}$

${ }^{66}$ AHPSse, Libro cabildo 4768(1772-1778) 05/05/1775, f. 179v.

${ }^{67}$ AHPSse, Libro cabildo 4768(1772-1778) 24/05/1778, f. 340v y 340r.
} 
En 1779, un memorial presentado por Joseph Alvarazin y Troya, presbítero, vecino de Sevilla, solicitaba que la Misericordia le nombrase capellán mayor del Pozo Santo por tener todas las cualidades para aquel oficio, además era "pobre cargado de familia", y haber estudiado filosofía y teología. Por años había sido teniente de cura de la iglesia parroquial de San Pedro y tenía corriente su licencia de confesar hombres y mujeres. La contaduría informó que aquella capellanía ofrecía 1500 reales anuales y casa. El capellán tenía la obligación de confesar y decir misa fundada por Ana de Trujillo a 6 reales de limosna que al año acumulaban 128 reales, sujetas a los vaivenes de la finca. Este cargo se hallaba vacante por desistimiento hecho por Antonio Fortanez que había sido nombrado por cabildo extraordinario el 24 de mayo de 1778, por jubilación de Joseph Avalos. ${ }^{68}$ Sin embargo, al cabo de un mes, la madre mayor se quejó del capellán José de Alvarazin ante el cabildo. ${ }^{69}$

En 1783, la madre Isabel de San Cristóbal fue nombrada como madre mayor. ${ }^{70}$ Ese mismo año, Clara Chamorro y Sotomayor quedó como única beneficiaria del testamento de Manuel Larios. Había fundado un vínculo en favor de ciertas personas y de mujeres de su linaje, disponiendo que a falta de ellas recayeran sus fincas en el Pozo Santo para los fines que dejaba dispuesto. El cabildo debía resolver lo que estimara, mandando dar certificación para presentarla en el juzgado de testamentos. El padre mayor firmó decreto para que el abogado Nicolás de Herrera reconociera los testimonios que se presentaban, es decir el testamento y codicilo de Martín Larios realizado ante Antonio de Madariaga, secretario público de Sevilla, en 11 y 23 de noviembre de 1778, en que nombró por una de sus albaceas a la citada doña Clara dándole amplias facultades para la admisión del caudal, fundando un vínculo en favor de su sobrina María de los Dolores Aguirre, para que residiese y estudiase en el convento de Santa Clara de Sevilla, hija de don Francisco Javier de Aguirre y de doña Ana Larios, vecinos del reino de Guatemala, y sus hijos si llegare el caso de tomar estado de casada y si fuese religiosa debía el día de su profesión pasar a su hermano Luis Pedro de Aguirre y Larios, ausente. Si hubiese falta de sucesión entonces los bienes del citado vínculo pasarían al hospital del Santo Cristo de los Dolores de la que destinaría 300 reales algo más o menos para el costo de una fiesta anual de Nuestra Señora del Tránsito. El resto del dinero sería destinado a mantener una o más camas de enfermas. $^{71}$

En 1785, nombramiento de la madre mayor Isabel del Espíritu Santo y su ayudante Isabel de San Cristóbal. ${ }^{72}$ En 1787 y 1788, relección de madre mayor Isabel del Espíritu Santo y su ayudante Isabel de San Cristóbal. ${ }^{73}$ En 1789,1791 y 1793 fueron reelegidas las mismas. ${ }^{74}$

\footnotetext{
${ }^{68}$ AHPSse, Libro cabildo 4769(1778-1786) 19/ 10/1779, f. 58 v-59 r-v.

${ }^{69}$ AHPSse, Libro cabildo 4769(1778-1786) 13/ 11/1779, f. 69rv

${ }^{70}$ AHPSse, Libro cabildo 4769(1778-1786) 04/05/1783, f.256r

${ }^{71}$ AHPSse, Libro cabildo 4769(1778-1786) 02/ 11/1783, f.278r-279v.

${ }^{72}$ AHPSse, Libro cabildo 4769(1778-1786) 30/ 04/1785, f.346v.

${ }^{73}$ AHPSse, Libro capitular de acuerdos y cabildos y juntas que se hacen en la Misericordia 4770(1786-1797) 05/03/1787 f.23. ADPS. Cartas a la madre mayor, legajo 1, s/f. La madre mayor Isabel del Espíritu Santo enviaba estampas de Nuestra Señora del Transito según consta en la carta mandada a la madre el 12 de agosto de 1786.

${ }^{74}$ AHPSse, Libro capitular de acuerdos y cabildos y juntas que se hacen en la Misericordia 4770(1786-1797) 02/05/1789, f. 95v. Libro capitular de acuerdos y cabildos y juntas que se hacen en la Misericordia 4770(1786-1797) 04/06/1791, f. 180r-v Libro capitular de acuerdos y cabildos y juntas que se hacen en la Misericordia 4770(1786-1797) 06/06/1795, f. 347vv
} 
Una madre mayor pidió que se la exonerase del cargo, pero el cabildo accedió a que eligiese la ayudante que necesitara para ayudarla y aliviara su trabajo, descargándosela a la madre ayudante. En 1798, la madre mayor del Pozo Josefa de Santa Gertrudis renunció a su cargo por su mala salud, que no le permitía dar cumplimiento a las obligaciones de su empleo, pidiendo al cabildo el desistimiento formal y su exoneración. El cabildo accedió que la madre segunda se ocupara de todos los asuntos que la madre mayor no pudiese poner en práctica por su falta de salud y que si necesitara alguna compañera que le ayudara, la madre mayor la eligiera de las demás asistentes del hospital a su voluntad. ${ }^{75}$ En 1799 se reformaron las reglas del Pozo. ${ }^{76}$

\section{Las últimas madres del Pozo Santo y su rela- ción con la Casa Pía de la Misericordia}

En 1803, relección de Mercedes como madre mayor y a su ayudante la madre San Agustín. ${ }^{77}$ En 1805, la madre María Ana de San Agustín y la madre mayor Paula de las Mercedes comunicaron a la Misericordia que para hacer las provisiones de bacalao, potajes, leña, carbón y suplemento de pan, de la pasada cuaresma le había sido preciso a la actual madre mayor pedir prestado la cantidad de 2.720 reales y a la pasada los 9.762 reales cuyas dos partidas componían 12.492 reales y no pareciéndoles justo detener por más tiempo el pago de un dinero que les habían prestado por el bien del Pozo Santo. La madre mayor consideraba su deber quedar bien con estos sujetos para que repitiesen esta ayuda cuando se encontrara en apuros el Pozo. ${ }^{78}$

En 1819, la madre mayor María Teresa de San Basilio, las madres y las otras mujeres del Pozo Santo pidieron nombrar un diputado sacerdote que procediera al escrutinio y elección de la madre mayor y a quien pudiera acudir en los casos puramente espiritual como sucedía en los demás conventos y beaterios. Pero, la Misericordia no lo aceptó e indicó que era muy impropia e inconveniente su conducta y por lo tanto podría hacérseles varios cargos. ${ }^{79}$ Esta vez la Misericordia no despidió a la madre mayor sino que quedó en una amonestación.

Las camas ocupadas por enfermas que fallecían se sometían a un concurso público para volver a ocuparlas, poniendo avisos o edictos, comunicando la convocatoria. En fechas tan tardías como 1821, aún se llevaba a cabo esta costumbre. Así, el 20 de mayo, la madre mayor de las beatas daba cuenta de que había muerto María Barranco que ocupaba una de las camas de la dotación del Marques de Campo Nuevo y se acordó que se fijarían edictos por el término que prevenía la dotación. ${ }^{80}$ Algunas personas legaban testamentariamente una renta para mantener una cama a ocupar por un incurable y que era entregada a la persona que cumpliera con los requisitos impuestos por el testador. Una costumbre pía que se arrastraba desde siglos atrás en diferentes hospitales castellanos (Rivasplata, 2015, pp.81-118).

En 1821, el alcalde constitucional y presidente de la junta municipal, Feliz María Hidalgo, hizo saber que en virtud del decreto de

\footnotetext{
${ }^{75}$ AHPSse, Libro capitular de acuerdos y cabildos y juntas que se hacen en la Misericordia 4771(1797-1800)4/11/1798, p, 58v ${ }^{76}$ AHPSse, Libro capitular de acuerdos y cabildos y juntas que se hacen en la Misericordia 4771(1797-1800)1/18/1799 f, $92 \mathrm{r}$ ${ }^{77}$ AHPSse, Libro capitular de acuerdos y cabildos y juntas que se hacen en la Misericordia 4771(1797-1800)30/04/1803, f2210v

${ }^{78}$ AHPSse, Legajo 22302, 14/06/1805. ADPS. Libro de cuentas con la casa de la Misericordia (1783-1796)(1787-1821), legajo $15, \mathrm{~s} / \mathrm{f}$.

${ }^{79}$ AHPSse, Libro capitular de acuerdos y cabildos y juntas que se hacen en la Misericordia 4772(1808-1821)16/08/1819 s/f.

${ }^{80}$ AHPSse, Libro cabildo 4773(1821-1836) 20/05/1821.
} 
cortes del 27 de diciembre del próximo había determinado la referida junta pasar a tomar posesión de la casa de la Misericordia y hospital del Santo Cristo de los Dolores del cual el primero era administrador. ${ }^{81}$ En 1821, el Pozo Santo fue admitido por los muchos atrasos y deudas a no ser de los fondos que estaban a disposición de la junta parroquial por lo que se le asignaría cuota suficiente para su manutención. ${ }^{82}$ Un año después, el padre mayor hizo presente que a consecuencia del oficio visto en el cabildo anterior vinieron a tomar posición de esta casa y el Pozo Santo los comisionados por la junta municipal de beneficencia y que Feliz María Hidalgo como presidente de la junta había nombrado interinos de la casa al padre mayor Osorio y a los claveros que lo acompañaban. ${ }^{83}$

Otra vez, una cama pagada por una dotación en el Pozo Santo se ofreció en llamamiento público en 1825. El Pozo cumplió con el llamamiento público y los edictos, convocando a las que quisieren postular a la cama vacante de la dotación del marqués de Camponuevo, teniendo presente lo dispuesto por el fundador, los memoriales presentados y lo informado en ella. Una vez terminado la convocatoria y entrega de documentos se procedió a votar para su provisión y salió nombrada por mayor parte de votos, Basilia López. ${ }^{84}$ Otra cama del mismo patrono fue otorgado a Isabel Garina. ${ }^{85}$ En 1826, otra cama del mismo patrono lo ganó Rosa Morales. ${ }^{86}$

En 1828, madre mayor fue Carmen y su ayudante madre Jesús María. ${ }^{87}$ Y en 1830, la elección de la madre mayor recayó en Espíritu Santo y su ayudante la madre Nicolás. ${ }^{88}$ Asimismo, en 1832, fue reelegida la madre mayor Espíritu Santo y para segunda la madre Nicolás. ${ }^{89}$ Aún se nombraban capellanes en el Pozo Santo en 1836 cuando se presentó vacancia para la capellanía mayor del Pozo por fallecimiento de José Morín, eligiéndose a don José Gil, además a la madre Asunción como madre mayor y a su ayudante a la madre Jesús. ${ }^{90}$

\section{CONCLUSIONES}

El beaterio y hospital del Pozo Santo se fundó a finales del siglo XVII. Asumió su patronato y administración externa la hermandad de la Misericordia que gestionaba la Casa Pía del mismo nombre, conocido como el "hospital de la Misericordia de Sevilla”. El beaterio hospital del Pozo Santo estaba dirigida internamente por una madre mayor, la cual tenía como responsabilidad velar por su mantenimiento y denunciar sus necesidades a su patrona, la Misericordia. Asumió a plenitud sus deberes y muchas veces sus iniciativas individuales fueron sólo comunicadas una vez realizadas.

\footnotetext{
${ }^{81}$ AHPSse, Libro cabildo 4773(1821-1836) 04/08/1821

82AHPSse, Libro cabildo 4773(1821-1836) 04/08/1821.

83AHPSse, Libro cabildo 4773(1821-1836) 26/08/1822

84AHPSse, Libro capitular de acuerdos y cabildos y juntas que se hacen en la Misericordia 4773 (1821-1836) 10/11/1825, f..66r.

${ }^{85}$ AHPSse, Libro capitular de acuerdos y cabildos y juntas que se hacen en la Misericordia 4773 (1821-1836) 23/12/1825,f.67v-r.

${ }^{86}$ AHPSse, Libro capitular de acuerdos y cabildos y juntas que se hacen en la Misericordia $4773(1821-1836) 02 / 05 / 1826, f .76 r$.

${ }^{87}$ AHPSse, Libro capitular de acuerdos y cabildos y juntas que se hacen en la Misericordia 4773 (1821-1836) 23/12/1825,f.67v-r. AHPSse, Libro capitular de acuerdos y cabildos y juntas que se hacen en la Misericordia 4773 (1821-1836) 11/05/1828,f.115v-116r.

${ }^{88}$ AHPSse, Libro capitular de acuerdos y cabildos y juntas que se hacen en la Misericordia 4773 (1821-1836) 02/05/1830,f.149r

${ }^{89}$ AHPSse, Libro capitular de acuerdos y cabildos y juntas que se hacen en la Misericordia 4773 (1821-1836) 27/05/1832,f.177v$178 \mathrm{r}$

${ }^{90}$ AHPSse, Libro capitular de acuerdos y cabildos y juntas que se hacen en la Misericordia $4773(1821-1836) 11 / 05 / 1836, f .241 \mathrm{r}$. f. $243 \mathrm{v}$ y $244 \mathrm{r}$
} 


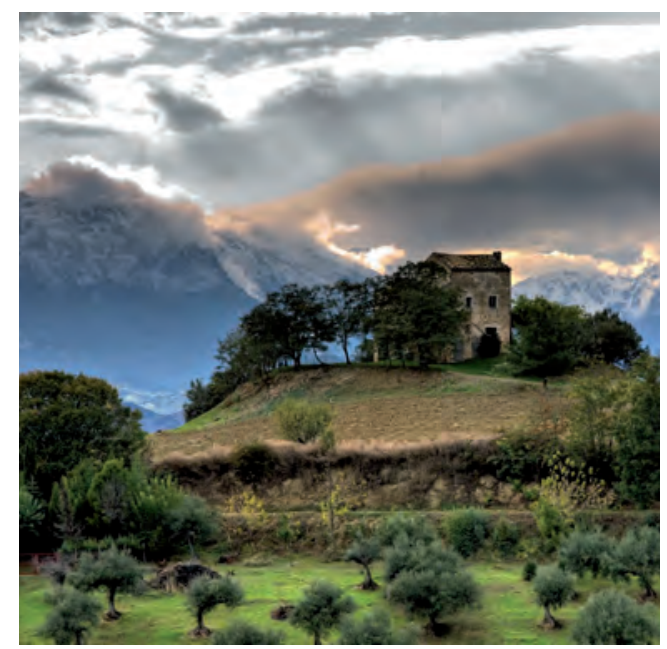

Exigía el dinero que le correspondía donado por testamento, denunciaba sus carencias o necesidades, recomendaba transacciones económicas que consideraba necesarias para el mantenimiento del establecimiento, solicitaba permiso para recaudar limosnas, etc. Sólo una vez la hermandad de la Misericordia siguiendo el consejo del procurador consideró que había extralimitado sus funciones y la madre mayor fue despedida junto al capellán en 1737. Aunque no se la arrojó del beaterio se la condenó al confinamiento y a no poder ejercer otra vez cargo alguno en el hospital. Mientras que al capellán se le expulsó. Esta decisión de la hermandad de la Misericordia fue mancomunada con el procurador del obispado sevillano. Sin embargo, paulatinamente, la madre mayor volvió a asumir su liderazgo y lo empezó la misma madre mayor recomendada por el procurador que expulso a la anterior. No cabiendo duda que la actitud demandante de la madre mayor obedecía a la necesidad de mantener en pie al hospital del Pozo Santo. Pronto las nuevas madres asumieron más responsabilidades y prerrogativas al grado que una de ellas inició el peregrinaje a la corte para pedir limosnas necesarias para el mantenimiento de la insti- tución y que se mantuvo como una costumbre entre algunas de las subsiguientes madres mayores. De esta manera se puede concluir que la madre mayor cumplió un papel crucial en el buen mantenimiento del hospital y, también, en la propagación de la fe de la Virgen del Transito Sevillana.

\section{BIBLIOGRAFÍA}

- Carmona, J. I. (1989). La reunificación de los hospitales sevillanos. En Los hospitales de Sevilla. Sevilla: Academia Sevillana de Buenas Letras.

- Collantes, F. (1884). Memorias históricas de los establecimientos de caridad de Sevilla y descripción artística de los mismos. Sevilla: Imprenta y Litografía de José María Ariza.

- Gonzales, J. (1967). III Centenario del Hospital del Pozo Santo: 1667-1967. Sevilla: Graficas Sevillanas.

- Gonzales, J. (2003). El Pozo Santo. Sevilla: Imprenta y Papelería Rojo.

- Ortiz de Zúñiga, D. (1796). Anales Eclesiásticos y Seculares de la muy noble y muy leal ciudad de Sevilla. Madrid: Imprenta Real.

- Rivasplata, P. E. (2014a). Las madres del buen morir del Hospital de las Cinco Llagas de Sevilla en el Antiguo Régimen. Erebea. Revista de Humanidades y Ciencias Sociales, 4, 81-118.

- Rivasplata, P. E. (2014b). La madre mayor del Hospital de las Cinco Llagas de Sevilla en el Antiguo Régimen. Hispania Sacra, LXVI (134), 134-184.

- Rivasplata, P. E. (2015). Las áreas de incurables del Hospital de la Sangre de Sevilla, Erebea. Revista de Humanidades y Ciencias Sociales, 5, 243-272.

- Roda, J. (2005). Un crucificado hispano-filipino de marfil en el hospital del pozo santo de Sevilla, Laboratorio de Arte, 18, 321-326 